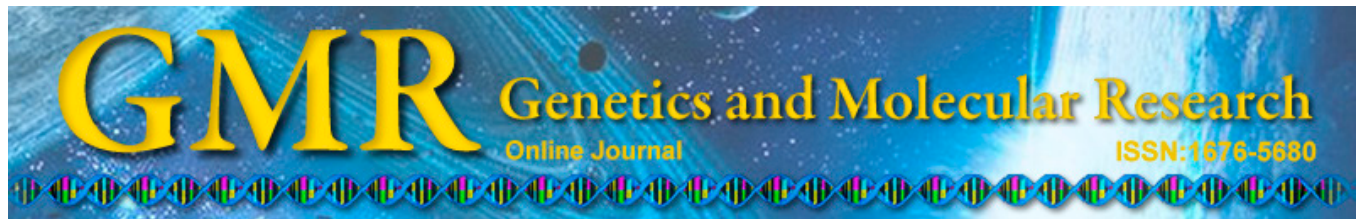

\title{
WY14643 combined with all-trans retinoic acid acts via p38 MAPK to induce "browning" of white adipocytes in mice
}

\author{
J. Wang', G.J. Sun ${ }^{1}$, J. Ding ${ }^{2}$, J.X. Zhang ${ }^{3}$, Y. Cui ${ }^{1}$, H.R. Li ${ }^{1}$ and S.J. Wang ${ }^{1}$ \\ ${ }^{1}$ Department of Endocrinology and Metabolism, the First Affiliated Hospital, \\ Zhengzhou University, Zhengzhou, China \\ ${ }^{2}$ Department of Obstetrics, the First Affiliated Hospital, Zhengzhou University, \\ Zhengzhou, China \\ ${ }^{3}$ Department of Breast Surgery, the First Affiliated Hospital, Zhengzhou University, \\ Zhengzhou, China
}

Corresponding author: S.J. Wang

E-mail: shoujunwangcn@163.com

Genet. Mol. Res. 14 (2): 6978-6984 (2015)

Received August 13, 2014

Accepted March 5, 2015

Published June 26, 2015

DOI http://dx.doi.org/10.4238/2015.June.26.6

ABSTRACT. The ability of mammals to resist body fat accumulation
is linked to their ability to expand the number of "brown adipocytes"
within white fat depots. All-trans retinoic acid (t-RA) and peroxi-
some proliferator-activated receptor- $\alpha$ (PPAR $\alpha$ ) have been implicated
in "browning-like" or "browning" programs, respectively. However,
a PPAR $\alpha$-agonist (WY14643) failed to regulate the expression of the
uncoupling protein 1(UCP1) gene unless combined with retinoic acid.
This study investigated the effects of the PPAR $\alpha$-agonist WY14643
combined with t-RA, on the "browning" of white adipocytes in mice
mediated by UCP1, and the molecular mechanisms involved in this
process. We compared the effects of WY14643 alone and WY14643
combined with t-RA or the p38 MAPK-inhibitor, SB203580, on white
adipocytes after $24 \mathrm{~h}$ using the expression of UCP1, detected with RT- 
PCR and western blot. We also determined the mechanism by which p38 MAPK and phospho-p38 MAPK influence the process of "browning" using western blot. All concentrations of WY14643 failed to induce UCP1 mRNA expression, protein expression, or phosphorylation of $\mathrm{p} 38$ MAPK $(\mathrm{P}<0.05)$. WY14643 combined with t-RA was observed to induce UCP1 mRNA expression, protein expression, and phosphorylation of p38 MAPK $(\mathrm{P}<0.05)$. SB203580 combined with WY14643 and t-RA suppressed UCP1 mRNA expression, protein expression, and p38 MAPK phosphorylation $(\mathrm{P}<0.05)$. WY14643 combined with t-RA can induce the transformation of white adipocytes to brown adipocytes through activation of the p38 MAPK signaling pathway.

Key words: Brown adipocytes; Proliferator-activated receptor- $\alpha$; All-trans retinoic acid; Uncoupling protein 1; p38 MAPK pathway

\section{INTRODUCTION}

There are two different types of adipose cells in mammals, white adipocytes and brown adipocytes. In contrast to the primarily fat-storing function of white adipose tissue (WAT), brown adipose tissue (BAT) has non-shivering, thermogenic properties due to the expression of the UCP1 and increased mitochondrial content (Ravussin and Galgani, 2011). In addition, higher BAT levels are associated with resistance to metabolic diseases (Zhou et al., 2003). Recent findings that exercise increases the relative amount of BAT (Dunstan, 2011; Boström et al., 2012) have stimulated interest concerning the therapeutic potential of augmenting brown fat to combat metabolic diseases.

PPAR $\alpha$, a member of the peroxisome proliferator-activated receptor (PPAR) family of ligand-activated receptors, can stimulate the expression of the PR domain containing 16 (PRDM16) gene in brown adipocytes, and PPAR $\alpha$ activation in white adipocytes has been found to induce the expression of brown fat markers (Yoon, 2009). A muscle-derived hormone, irisin, has recently been identified as promoting the induction of brown adipocytes in white fat. Investigations at the molecular level have found that one possible mechanism may be increased expression of PPAR $\alpha$, while pharmacological inhibition with a PPAR $\alpha$-selective antagonist limited the induction of the "browning" program by irisin (Castillo-Quan, 2012). However, the PPAR $\alpha$-agonist WY14643 failed to regulate the expression of the UCP1 gene of white adipocytes unless combined with retinoic acid (RA) (Oberkofler et al., 2002; Mercader et al., 2006; Beranger et al., 2013).

RA can reduce body weight, increase body temperature, and increase adiposity in rodent models, and stimulates UCP1 expression in brown adipose tissue and skeletal muscle. Furthermore, administration of t-RA results in reduced adiposity and adipocyte cell size with a rise in multilocular adipocytes expressing brown fat markers in white fat depots (Bonet et al., 2012).

Due to the increasing interest in the mechanisms involved in the transformation of white adipocytes to brown adipocytes, there is an absolute necessity for cellular models to unravel the mechanisms of the PPAR $\alpha$-agonist WY14643, combined with t-RA, on the "browning" of white adipocytes in mice, to help elucidate more mechanistic details. 


\section{MATERIAL AND METHODS}

\section{Cell culture and differentiation}

Mice 3T3-L1 preadipocytes (BOSTER, Wuhan, China) were cultured in growth medium [high glucose Dulbecco's Modified Eagle's Medium (DMEM) containing 1\% antibioticantimycotic solution and $10 \%$ fetal bovine serum (FBS)] at $37^{\circ} \mathrm{C}$ in a humidified atmosphere with $5 \% \mathrm{CO}_{2}$. When reaching confluency, the cells were differentiated in growth medium containing 0.5 mM IBMX (Sigma-Aldrich, America), $1.0 \mu \mathrm{M}$ dexamethasone (Sigma-Aldrich), and $2 \mathrm{mg} / \mathrm{L}$ insulin (Sigma-Aldrich). After 2 days, cells received fresh growth medium containing $2 \mathrm{mg} / \mathrm{L}$ insulin. After 4 days, cells received fresh growth medium without additives and cells were replenished with the same medium every 2 days for 8 days. Oil Red $\mathrm{O}$ staining for lipid droplets was used to evaluate adipocyte differentiation.

\section{RT-PCR}

Cells were plated on six-well plates $\left(8 \times 10^{4}\right.$ cells/well $)$ and cultured for $24 \mathrm{~h}$. In treatment 1, the cells were exposed to $2.5 \mu \mathrm{M}, 5 \mu \mathrm{M}$, and $10 \mu \mathrm{M}$ WY14643 (Santa Cruz Biotechnology, USA) for $24 \mathrm{~h}$. In treatment 2, cells were first exposed to $0 \mathrm{mM}, 10^{-5} \mathrm{mM}, 10^{-4} \mathrm{mM}$, $10^{-3} \mathrm{mM}, 10^{-2} \mathrm{mM}$, and $10^{-1} \mathrm{mM}$ t-RA (Sigma-Aldrich) for $24 \mathrm{~h}$. Then, $5 \mu \mathrm{M}$ WY14643 was added for $24 \mathrm{~h}$. In treatment 3, cells were exposed to $10 \mu \mathrm{M}$ SB203580 (Santa Cruz Biotechnology) for $24 \mathrm{~h}$, followed by $0 \mathrm{mM}, 10^{-5} \mathrm{mM}, 10^{-4} \mathrm{mM}, 10^{-3} \mathrm{mM}, 10^{-2} \mathrm{mM}$, and $10^{-1} \mathrm{mM}$ t-RA for $24 \mathrm{~h}$, and finally, $5 \mu \mathrm{M}$ WY14643 was added for $24 \mathrm{~h}$.

Total RNA was extracted from cells using TRIzol Lysis Reagent (TaKaRa, Japan) according to the manufacturer protocol. First-strand complementary DNA (cDNA) was synthesized using $3 \mu \mathrm{g}$ total RNA as the template, $500 \mathrm{ng}$ random primer, and the cDNA synthesis kit components (TransGen, Beijing, China) in a total volume of $25 \mu \mathrm{L}$, according to the manufacturer protocol. The targeted fragment of cDNA for the brown adipocyte differentiationassociated gene UCP1 (Table 1) was amplified by PCR using $1 \mu \mathrm{L}$ RT product, 10 pmol each primer, and the PCR premix.

\begin{tabular}{|c|c|}
\hline Gene & Primer sequences \\
\hline \multirow[t]{2}{*}{$\mathrm{UCP} 1$} & F:5'-GTACCACATAAGCAACTTGGAG-3' \\
\hline & R:5'-ATCTTGTAATGTAAATAAAGTC-3' \\
\hline \multirow[t]{2}{*}{$\beta$-actin } & F:5'-GAGACCTTCAACACCCCAGC-3' \\
\hline & R:5'-AGCATTGTAGGTCCCCGTGT-3' \\
\hline
\end{tabular}

UCP-1, uncoupling protein-1.

\section{Western blot}

Cells were exposed to the same three treatments as described in the previous section and then washed 3 times with ice-cold PBS and harvested in ice-cold RIPA buffer containing a protease inhibitor and phosphatase inhibitor cocktail (BOSTER). Protein concentrations were measured with a BCA protein assay kit. Protein was mixed with $5 \mathrm{X}$ sample buffer and boiled for $7 \mathrm{~min}$, leaving $25 \mu \mathrm{L}$ of sample remaining after cooling. The cell lysates were separated by 
sodium dodecyl sulfate polyacrylamid gel electrophoresis (SDS-PAGE) and polyvinylidene fluoride (PVDF) membranes. The membranes were blocked with 5\% instant skimmed-milk powder, spray-dried in tris-buffered-saline with tween (TBST) for $1 \mathrm{~h}$, and then incubated at $4^{\circ} \mathrm{C}$ overnight with the appropriate antibody at a 1:1000 dilution in TBS (Anti-phospho-p38 MAPK and anti-p38 MAPK were from CST, USA, anti-UCP1 was from ABgent, USA). After washing, the PVDF membranes were incubated at normal temperature with horseradish peroxidase-conjugated anti-rabbit IgG (Sigma-Aldrich) at a 1:5000 dilution in TBS for $1 \mathrm{~h}$. After washing, images were analyzed using the Image Studio v2.0 software.

\section{Statistical analysis}

Results are reported as means \pm SD unless otherwise indicated. Data were analyzed using one-way ANOVA and LSD- $t$ tests. Differences were considered to be statistically significant at $\mathrm{P}<0.05$. The SPSS 17.0 software was used for statistical analyses; $\mathrm{P}$ values for significance are indicated for each data set.

\section{RESULTS}

\section{Morphology of 3T3-L1 preadipocytes}

Before differentiation, mice 3T3-L1 cells were spindle-shaped, with no lipid droplets in the cytoplasm, and had a fibroblast-like morphology (Figure 1A). After complete confluence, cells were in growth arrest. After 4 days of differentiation, cells were large and round, with some lipid droplets appearing in some cells. After 8 days of differentiation, preadipocytes were differentiated into mature adipocytes, showing larger, rounder, abundant cytoplasm and a large number of lipid droplets (Figure 1B and C). Lipid accumulation was assessed in fixed cells using Oil-red-O staining (Figure 1D). These results clearly demonstrate that 3T3-L1 preadipocyte cells differentiated into mature white adipocytes.

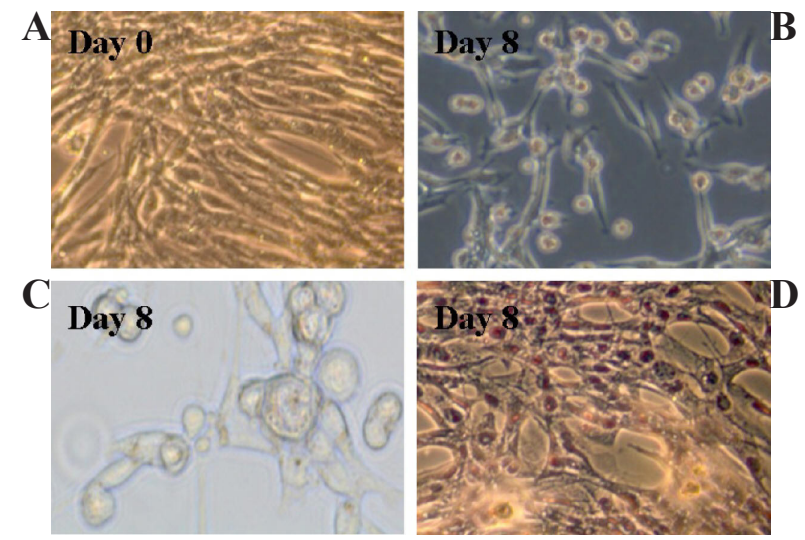

Figure 1. Morphology of 3T3-L1 preadipocytes after differentiation. 3T3-L1 preadipocytes are fibroblastic, there are not fat droplets in cytoplasma (Day 0,100X). On the 8th day after induction with hormones, a lot of cells were differentiated. There were lots of fat droplets in the cells which became much bigger and rounder (Day 8 , $100 \mathrm{X} / 400 \mathrm{X})$. On the 8 th day after induction with hormones, the fat droplets in adipocyte were stained by RedOil-O (Day 8, 400X). 


\section{Role of WY14643 combined with t-RA}

Since the white adipocytes of mice do not express UCP1 gene, we examined whether WY14643 combined with t-RA could induce expression of UCP1 gene. In these experiments, we used differentiated mice multipotent adipose-derived 3T3-L1 preadipocytes. Treatment with WY14643 over a range of concentrations from 2.5 to $10 \mu \mathrm{M}$ was unable to significantly induce transcripts of UCP1 gene; but WY14643 combined with t-RA significantly induced transcripts of UCP1 gene, as shown in Figure $2 \mathrm{E}$ and F.

Western blot analysis (Figure 2G and H) showed that the ability of WY14643 combined with t-RA to trigger expression was synchronous to the effect of induced phosphorylation of $\mathrm{p} 38$ MAPK. Since $\mathrm{p} 38$ MAPK activation results in UCP1 production, we assessed the role of p38 MAPK to induce the brown adipocyte marker. However, pretreatment with SB203580, which is a p38 MAPK inhibitor, completely blocked the effect of WY14643 combined with t-RA, suggesting that p38 MAPK activity is important for "browning" of white adipocytes.

A

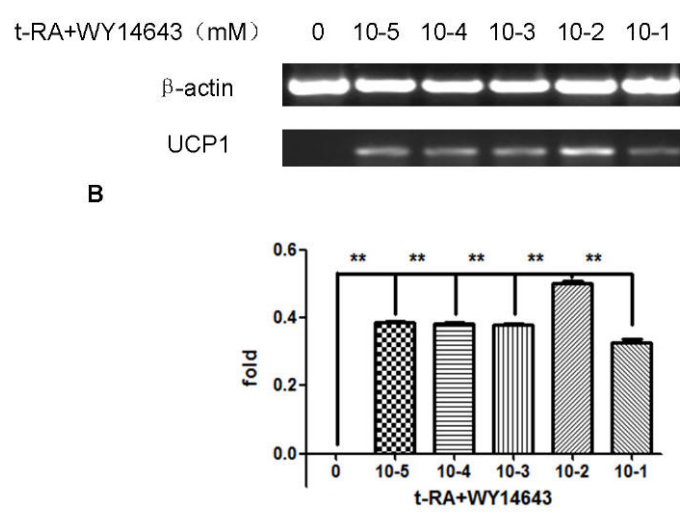

C

t-RA+WY14643(mM) $0 \quad 10-5 \quad 10-4 \quad 10-3 \quad 10-2 \quad 10-1$

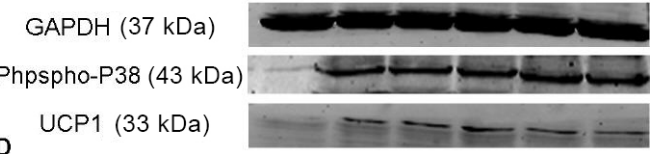

D

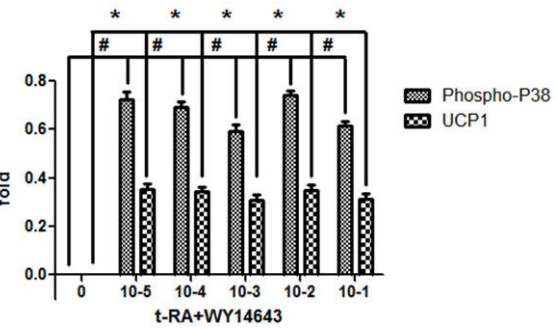

Figure 2. Effect of WY14643 combined with t-RA on browning of mice white adipocytes. (A-B) Brown adipocytespecific gene UCP1 expression was analyzed by RT-PCR (A) and densitometry (B). Data are reported as means percentage levels $\pm \mathrm{SD}$ (means $\pm \mathrm{SD} ; \mathrm{N}=3 ;{ }^{* *} \mathrm{P}<0.01$ ). (C-D) Analysis of phosphor -P38 and UCP1 expression by Western blot $(\mathrm{C})$ and densitometry $(\mathrm{D})$. Data are reported as means percentage levels $\pm \mathrm{SD}$ (means $\pm \mathrm{SD} ; \mathrm{N}=$ $\left.3 ;{ }^{*} \mathrm{P}<0.01 ;{ }^{\#} \mathrm{P}<0.01\right)$.

\section{DISCUSSION}

Evidence has accumulated that the impact of retinoic acid on developmental and biochemical processes influences mammalian adiposity, including adipocyte differentiation and lipogenesis, adaptive thermogenesis, lipolysis, and fatty acid oxidation in tissues (Bonet et al., 2012). Treatment with retinoic acid, in particular, has been shown to reduce body fat, improve insulin sensitivity, and induce UCP1 expression in brown adipose tissue and skeletal muscle cells in lean and obese rodents (Mercader et al., 2010). Retinoic acid has gained increasing attention because of its multiple effects on the biological characteristics of adipocytes, including the impact on the thermogenic capacity of brown fat, and the oxidative and secretory capacity of white fat. t-RA has a role in promoting cell differentiation, distribution of intracellular, and cell's protein synthesis, amino acid uptake and expression of metabolic enzymes (Manolescu 
et al., 2010). PPARs (PPAR $\alpha$, PPAR $\beta$, and PPAR $\gamma$ ) may modulate these metabolic risk factors, suggesting that activation of PPARs may be an effective therapy for several diseases associated with metabolic syndrome. Thus, PPARs have been the subject of intense investigation and considerable pharmacological research (Kliewer et al., 1999; Kersten et al., 2000; Evans et al., 2004). Studies have shown that PPAR $\alpha$ controls a large number of genes related to the metabolism of lipo-protein. PPAR $\alpha$ activation also mediates improvements in glucose and energy homeostasis (Pineda et al., 1999) and modulates the expression of UCPs, such as increasing the level of UCP1 mRNA in brown adipose tissue, UCP2 mRNA in liver, and UCP3 mRNA in skeletal muscle (Brun et al., 1999; Barbera et al., 2001; Nakatani et al., 2002).

WY14643, as a PPAR $\alpha$ agonist, has been shown to improve the level of UCP3 mRNA in mice preadipocytes and inhibit free fatty acid synthesizing triglycerides in white adipose tissue, thus, it is involved in the regulation of obesity and lipid metabolism (Cabrero et al., 2000). However, WY14643 failed to regulate the expression of the UCP1 gene unless combined with retinoic acid, and the mechanism is unknown. Due to the fact that RA impacting on lipid metabolism involves the modulation of the activity of several important protein kinases, for example, the p38 mitogen-activated protein kinase (p38 MAPK) (Lee et al., 2008), we infer that "browning" of white adipocytes induced by WY14643 combined with t-RA has a relationship with p38 MAPK. In the current study, WY14643 alone, WY14643 combined with t-RA, and WY14643 combined with t-RA and the p38 MAPK inhibitor SB203580 were used to treat white adipocytes from mice. According to the results of the RT-PCR and western blot, WY14643 alone failed to regulate the expression of UCP1. However, WY14643 combined with t-RA induced the expression of UCP1, which could be blocked by pretreatment with SB203580, a p38 MAPK inhibitor. Perhaps this is because p38 MAPK activity is a key link for the "browning" of white adipocytes induced by WY14643.

Boström et al. (2012) revealed part of the molecular mechanisms of how exercise promotes the occurrence of "browning." They found that exercise (particularly chronic) is accompanied by increased expression of PGC-1 $\alpha$ in muscle. Muscle-specific overexpression of PGC-1 $\alpha$ induced a brown-like adipose tissue gene program, including increased UCP1 expression in WAT through stimulation of irisin, a secreted molecule from muscle cells, which was responsible for inducing "browning" of WAT (Boström et al., 2012). Gene arrays indicated that one possible mechanism of irisin might be increased expression of PPAR- $\alpha$. Moreover, pharmacological inhibition with a PPAR- $\alpha$-selective antagonist limited the induction of the "browning" program by irisin (Castillo-Quan, 2012). Referring to the results of this experiment, activation of the p38 MAPK signaling pathway may be the necessary precondition for activation of PPAR $\alpha$ to promote "browning" of white adipocytes. Therefore, we infer that the newfound substance irisin also activates the p38 MAPK signaling pathway in the "browning" program. Whether activation of the p38 MAPK pathway is the precondition for "browning" of white adipocytes in mammal is worth further exploration.

\section{ACKNOWLEDGMENTS}

Research supported by the Science and Technology Innovation Team Fund Project of Zhengzhou (\#131PCXTD631). The authors acknowledge the contribution of former and present members of the Key Laboratory of Henan Universities. We also thank Professor Zujiang Yu, Department of Infection, the First Affiliated Hospital of Zhengzhou University, for his helpful assistance. 


\section{REFERENCES}

Barbera MJ, Schluter A, Pedraza N, Iglesias R, et al. (2001). Peroxisome proliferator-activated receptor alpha activates transcription of the brown fat uncoupling protein-1 gene. A link between regulation of the thermogenic and lipid oxidation pathways in the brown fat cell. J. Biol. Chem. 276: 1486-1493.

Beranger GE, Karbiener M, Barquissau V, Pisani DF, et al. (2013). In vitro brown and "brite"/“beige" adipogenesis: human cellular models and molecular aspects. Biochim. Biophys. Acta 1831: 905-914.

Bonet ML, Ribot J and Palou A (2012). Lipid metabolism in mammalian tissues and its control by retinoic acid. Biochim. Biophys. Acta 1821: 177-189.

Boström P, Wu J, Jedrychowski MP, Korde A, et al. (2012). A PGC1- $\alpha$-dependent myokine that drives brown-fat-like development of white fat and thermogenesis. Nature 481: 463-468.

Brun S, Carmona MC, Mampel T, Viňas O, et al. (1999). Activators of peroxisome proliferator-activated receptor-alpha induce the expression of the uncoupling protein-3 gene in skeletal muscle: a potential mechanism for the lipid intakedependent activation of uncoupling protein-3 gene expression at birth. Diabetes 48: 1217-1222.

Cabrero A, Alegret M, Sánchez R, Adzet T, et al. (2000). Peroxisome proliferator-activated receptor $\alpha$ (PPAR $\alpha$ ) activators, bezafibrate and Wy-14,643, increase uncoupling protein-3 mRNA levels without modifying the mitochondrial membrane potential in primary culture of rat preadipocytes. Arch. Biochem. Biophys. 380: 353-359.

Castillo-Quan JI (2012). From white to brown fat through the PGC-1 $\alpha$-dependent myokine irisin: implications for diabetes and obesity. Dis. Model. Mech. 5: 293-295.

Dunstan D (2011). Diabetes: exercise and T2DM-move muscles more often! Nat. Rev. Endocrinol. 7: 189-190.

Evans RM, Barish GD and Wang YX (2004). PPARs and the complex journey to obesity. Nat. Med. 10: 355-361.

Kersten S, Desvergne B and Wahli W (2000). Roles of PPARs in health and disease. Nature 405: 421-424.

Kliewer SA, Lehmann JM and Willson TM (1999). Orphan nuclear receptors: shifting endocrinology into reverse. Science 284: 757-760.

Lee YM, Lee JO, Jung JH, Kim JH, et al. (2008). Retinoic acid leads to cytoskeletal rearrangement through AMPK-Rac1 and stimulates glucose uptake through AMPK-p38 MAPK in skeletal muscle cells. J. Biol. Chem. 283: 33969-33974.

Manolescu DC, Sima A and Bhat PV (2010). All-trans retinoic acid lowers serum retinol-binding protein 4 concentrations and increases insulin sensitivity in diabetic mice. J. Nutr. 140: 311-316.

Mercader J, Ribot J, Murano I, Felipe F, et al. (2006). Remodeling of white adipose tissue after retinoic acid administration in mice. Endocrinology 147: 5325-5332.

Mercader J, Palou A and Bonet ML (2010). Induction of uncoupling protein-1 in mouse embryonic fibroblast-derived adipocytes by retinoic acid. Obesity 18: 655-662.

Nakatani T, Tsuboyama-Kasaoka N, Takahashi M, Miura S, et al. (2002). Mechanism for peroxisome proliferatoractivated receptor-alpha activator-induced up-regulation of UCP2 mRNA in rodent hepatocytes. J. Biol. Chem. 277: 9562-9569.

Oberkofler H, Esterbauer H, Linnemayr V, Strosberg AD, et al. (2002). Peroxisome proliferator-activated receptor (PPAR) gamma coactivator-1 recruitment regulates PPAR subtype specificity. J. Biol. Chem. 277: 16750-16757.

Pineda TI, Gervois P and Staels B (1999). Peroxisome proliferator-activated receptor alpha in metabolic disease, inflammation, atherosclerosis and aging. Curr. Opin. Lipidol. 10: 151-159.

Ravussin E and Galgani JE (2011). The implication of brown adipose tissue for humans. Annu. Rev. Nutr. 31: 33-47.

Yoon M (2009). The role of PPAR $\alpha$ in lipid metabolism and obesity: focusing on the effects of estrogen on PPAR $\alpha$ actions. Pharmacol. Res. 60: 151-159.

Zhou Z, Yon TS, Chen Z, Guo K, et al. (2003). Cidea-deficient mice have lean phenotype and are resistant to obesity. Nat. Genet. 35: 49-56. 